COMMENTARY ON COVID-19 AND THE FoOd SYSTEM

\title{
Providing planetary health diet meals to low-income families in Baltimore City during the COVID-19 pandemic
}

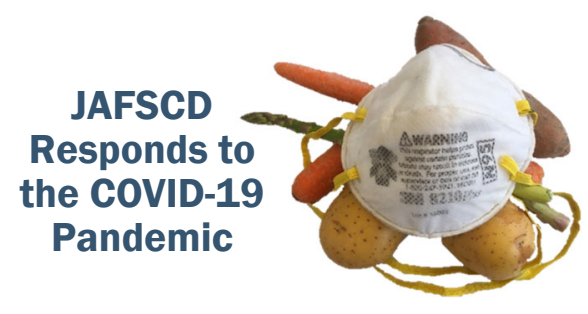

\author{
Richard D. Semba a* \\ Johns Hopkins University School of Medicine and Johns Hopkins Center for a Livable Future
}

Rebecca Ramsing ${ }^{b}$

Johns Hopkins Center for a Livable Future

Nihaal Rahman ${ }^{\mathrm{c}}$

Johns Hopkins Center for a Livable Future

Martin W. Bloem ${ }^{\mathrm{d}}$

Johns Hopkins Center for a Livable Future

Submitted September 20, 2020 / Published online October 19, 2020

Citation: Semba, R. D., Ramsing, R., Rahman, N., \& Bloem, M. W. (2020). Providing planetary health diet meals to low-income families in Baltimore City during the COVID-19 pandemic. Journal of Agriculture, Food Systems, and Community Development, 10(1), 205-213. https://doi.org/10.5304/jafscd.2020.101.010

Copyright (C) 2020 by the Authors. Published by the Lyson Center for Civic Agriculture and Food Systems. Open access under CC-BY license.

\begin{abstract}
The COVID-19 pandemic has increased food insecurity, especially among low-income Black and Hispanic families in the United States. Food insecurity is associated with poorer health and higher mortality

a * Corresponding author: Richard D. Semba, MD, MPH, Professor, Johns Hopkins University School of Medicine, and Affiliated Faculty, Johns Hopkins Center for a Livable Future, Johns Hopkins Bloomberg School of Public Health; Smith Building, M015, 400 North Broadway; Baltimore, MD 21287 USA; +1-410-955-3572; rdsemba@jhmi.edu

b Rebecca Ramsing, Senior Program Officer, Johns Hopkins Center for a Livable Future, Bloomberg School of Public Health; rramsin2@jhu.edu

c Nihaal Rahman, Research Assistant, Johns Hopkins Center for a Livable Future, Bloomberg School of Public Health; nrahma14@jhu.edu

d Martin Bloem, Professor, Department of Environmental Health and Engineering, and Director, Johns Hopkins Center for a Livable Future, Bloomberg School of Public Health, Johns Hopkins University; mbloem1@jhu.edu

Funding Disclosure

This commentary was supported by the Santa Barbara Foundation. The foundation had no role in the commentary, which is the viewpoint of the authors.

Acknowledgments

We thank Irena Stein, Emily Lerman, and Aishah Alfadhalah of Alkimiah for providing sample menus and allowing the food survey to be conducted with their participants. Food That Connects Us All is run by Alkimiah (a collaboration of Mera Kitchen Collective and Alma Cocina Latina).
\end{abstract}


in adults and greater risk of impaired cognitive development and behavioral problems in children. Providing food for low-income families is an important priority of the COVID-19 response. Food That Connects Us All is a program that provides healthy meals to low-income Black and Hispanic families in Baltimore City. The meals follow guidelines for the planetary health diet, a reference diet developed by the EAT-Lancet Commission to optimize health and be sustainable within planetary boundaries. The planetary health diet consists largely of vegetables, fruit, whole grains, legumes, nuts, and unsaturated oils, with a low to moderate amount of seafood and poultry and with little or no red or processed meats, refined grains, starchy vegetables, and added sugar. In a food survey, participants showed a high level of satisfaction with the taste, appearance, and healthfulness of the meals. Food That Connects Us All is a direct approach to reducing health disparities and demonstrates the feasibility of providing an ideal reference diet to vulnerable low-income families at high risk for poor health outcomes during the pandemic.

\section{Keywords}

COVID-19, EAT-Lancet, Food Insecurity, Planetary Health Diet, Minority Health, Sustainability

\section{Food Insecurity and COVID-19}

Food insecurity, defined as the limited or uncertain availability of nutritionally adequate and safe foods or limited or uncertain ability to acquire acceptable foods in socially acceptable ways (Holben \& Marshall, 2017), affected $11.1 \%$ of households in the U.S. prior to the COVID-19 pandemic (U.S. Department of Agriculture Economic Research Service [USDA ERS], 2020). In 2018, 13.9\% of households with children under age 18 years were food insecure (USDA ERS, 2020). Blacks and Hispanics are at a relatively higher risk of food insecurity (Hernandez, Reesor, \& Murillo, 2017). Poverty, unemployment, and the high cost of food are closely tied to household food insecurity (Huang, Kim, \& Birkenmaier, 2016). Food insecurity is associated with poor dietary quality, particularly a low intake of fruit, vegetables, and dairy products (Hanson \& Connor, 2014).

Adults affected by food insecurity have a higher risk of obesity, chronic diseases, and mortality (Brown et al., 2019; Cook et al., 2004; Seligman, Laraia, \& Kushel, 2010; Walker et al., 2019). Children are particularly affected by food insecurity; children from food-insecure households have higher morbidity (Cook et al., 2004; Ryu \& Bartfeld, 2012) and increased risk of impaired cognitive development and behavioral problems (Alaimo, Olson, \& Frongillo, 2001; Whitaker, Phillips, \& Orzol, 2006). In addition, their mothers are at higher risk of depression and anxiety (Whitaker et al., 2006). Programs to address food insecurity in the U.S. include the Supplemental Nutrition Assistance Program (SNAP), Special Supplemental Nutrition Program for Women, Infants, and Children (WIC), food banks, and community food programs (Loopstra, 2018). SNAP reached approximately 37 million people during the period of October 2019 to February 2020 (USDA Food \& Nutrition Service, 2020a). There were 6.4 million participants in WIC in 2019 (USDA Food \& Nutrition Service, 2020b). Under normal circumstances, the USDA National School Lunch Program, School Breakfast Program, and Children and Adult Care Food Program serve nearly 35 million children daily (USDA Economic Research Service, n.d.).

The COVID-19 pandemic has disrupted food supply chains and food access, caused massive job losses, especially among Blacks and Hispanics (Montenovo et al., 2020; U.S. Department of Labor, 2020) and has greatly exacerbated food insecurity (Niles et al., 2020). With the interruption of food programs and increases in food insecurity, feeding adults and children from low-income families has become an important priority of the COVID-19 response (Dunn, Kenney, Fleischhacker, \& Bleich, 2020). Federal nutrition programs have been given greater flexibility on the state level to deal with the evolving situation. The U.S. Congress' Families First Coronavirus Act (FFCA) included provisions to expand federal assistance to US $\$ 114$ per child per month and increase SNAP allotments up to the maximum benefit 
amount, but many households with children are already at the maximum amount (Kinsey, Kinsey, \& Rundle, 2020). Given the lack of federal guidelines, an uneven patchwork of support has emerged across the country, causing concerns that COVID-19 will exacerbate existing health disparities and have profound lasting negative impacts (Kinsey et al., 2020).

\section{The Planetary Health Diet}

In 2019, the EAT-Lancet Commission proposed an ideal diet known as the 'planetary health diet' (EATLancet, 2020; Willett et al., 2019). The diet is based on the best nutritional evidence available for optimizing health (defined by the World Health Organization as a state of complete physical, mental, and social well-being, and not just absence of disease [Preamble to the Constitution of WHO, 1948]) without surpassing planetary boundaries. The planetary health diet is a universal healthy reference diet that consists largely of vegetables, fruit, whole grains, legumes, nuts, and unsaturated oils, with a low to moderate amount of seafood and poultry and with little or no red or processed meats, added sugar, refined grains, and starchy vegetables (Table 1). The diet is sustainable within planetary boundaries for six environmental processes that include climate change, land-system change, freshwater use, biodiversity loss, and interference with the global nitrogen and phosphorus cycles (Willett et al., 2019).

Table 1. Composition of the Planetary Health Diet for an Intake of $2500 \mathrm{kcal} / \mathrm{day}$

\begin{tabular}{|c|c|c|c|}
\hline Food group & Foods & g/day & kcal/day \\
\hline Whole grains ${ }^{a}$ & rice, wheat, corn, other & 232 & 811 \\
\hline Tubers or starchy vegetables & potatoes, cassava & 50 & 39 \\
\hline \multirow{3}{*}{ Vegetables } & dark green vegetables & 100 & 23 \\
\hline & red and orange vegetables & 100 & 30 \\
\hline & other vegetables & 100 & 25 \\
\hline Fruits & all fruit & 200 & 126 \\
\hline Dairy foods & whole milk or equivalents & 250 & 153 \\
\hline \multirow{5}{*}{ Animal source proteins ${ }^{b}$} & beef, lamb & 7 & 15 \\
\hline & pork & 7 & 15 \\
\hline & chicken, other poultry & 29 & 62 \\
\hline & eggs & 13 & 19 \\
\hline & seafood $^{c}$ & 28 & 40 \\
\hline \multirow{4}{*}{ Plant source proteins $\mathrm{a}, \mathrm{d}$} & dry beans, lentils, peas & 50 & 172 \\
\hline & soy foods & 25 & 112 \\
\hline & peanuts & 25 & 142 \\
\hline & tree nuts & 25 & 149 \\
\hline \multirow{3}{*}{ Added fats } & unsaturated oils ${ }^{\mathrm{e}}$ & 40 & 354 \\
\hline & palm oil & 6.8 & 60 \\
\hline & lard or tallow & 5 & 36 \\
\hline Added sugars & all sweeteners & 31 & 120 \\
\hline
\end{tabular}

a Wheat, rice, dry beans, and lentils are dry, raw. ${ }^{b}$ Beef and lamb are exchangeable with pork and vice versa. Chicken and other poultry is exchangeable with eggs, fish, or plant protein sources. c Seafood consists of fish and shellfish. ${ }^{d}$ Legumes, peanuts, tree nuts, seeds, and soy are interchangeable. e Unsaturated oils are $20 \%$ each of olive, soybean, rapeseed, sunflower, and peanut oil.

Source: Willett et al., 2019. 


\section{Description of the Model Program}

A program known as Food That Connects Us All has served more than 50,000 meals in Baltimore City, Maryland, since the beginning of the COVID-19 pandemic. Food That Connects Us All was founded in mid-March 2020 by Alkimiah, a collaboration between the catering business Mera Kitchen Collective and the restaurant Alma Cocina Latina. It was created to address food insecurity in response to the pandemic. Alkimiah has received funding and support from the World Central Kitchen, founded by Chef José Andrés. Fresh fruit and vegetables, dairy products, and chicken are sourced from local organic farms, as much as possible, or received as donations of excess fresh produce from farms in Maryland and Pennsylvania. Fish and meat are obtained from local purveyors. The coordinating chef plans the menu daily with five cooks in the kitchen of Alkimiah. The founding principles of Food That Connects Us All include providing healthy, sustainable diets to people in need. The meals generally follow guidelines for the planetary health diet (Table 1) (EAT-Lancet, 2020; Willett et al., 2019). Examples of meals include (1) salmon cakes with mixed seasonal vegetables, Israeli couscous, and creamy pesto sauce; (2) chicken salad with red peppers, green beans, mixed greens, caramelized onions, dried figs, quinoa, and fresh basil; (3) ground turkey chili with red kidney beans, polenta, local sweet corn, Latin coleslaw, and cilantro. The staff prepare approximately 500 meals per day in the early morning, and the meal boxes are distributed in the afternoon by distribution center volunteers. Food workers are paid a minimum of US $\$ 16 /$ hour in the project. The food distribution has included over 15 schools, community centers, and senior homes in Baltimore City, Monday through Saturday, 1:00 to 4:00 PM. Some meals are delivered by volunteers directly to families that are unable to come to the distribution centers. Since the distribution of meals is community-based, most recipients walk a short distance to the distribution centers. This program supports primarily low-income Hispanic families in areas of Baltimore City that are highpriority food areas (sometimes known as food deserts) (Franco, Diez Roux, Glass, Caballero, \& Brancati, 2008).

In order to evaluate the recipients' satisfaction with the meals provided by Food That Connects Us All, a survey was conducted consisting of six questions: (1) How do you like the taste of the food? Delicious/good/so so/not good/bad; (2) How do like the appearance of the food? Beautiful/nice/so so/not nice/not beautiful; (3) How healthy is the food? Very healthy/healthy/not sure/unhealthy/very unhealthy; (4) What is your overall satisfaction with the food? Love it/like it/so so/don't like/really don't like; (5) Would you recommend this food to a friend? Yes/no; (6) What would you change about the meal? Check any: Nothing/bigger portions/more vegetables/more variety. The survey was given in both English and Spanish. Of the approximately 500 people who regularly receive their meal boxes, 242 completed the survey in the period of August 17-24, for a response rate of $48.4 \%$. The results of the first four questions are shown in Figure 1. The responses were highly positive, such as $55.4 \%$ for delicious taste, $52.0 \%$ for beautiful appearance, $56.2 \%$ for very healthy, and for overall satisfaction, $55.8 \%$ love it. When asked "Would you recommend this food to a friend?" $96.2 \%$ responded yes and $3.8 \%$ responded no. When asked about changing anything about the meal, 36.8\% would not change anything, $32.2 \%$ wanted bigger portions, $14.4 \%$ wanted more vegetables, and $9.0 \%$ wanted more variety.

\section{Addressing Food Insecurity}

The COVID-19 pandemic may increase health disparities among low-income minority families due to loss of livelihood and exacerbation of food insecurity (Kinsey et al., 2020). To our knowledge, Food That Connects Us $A l l$ is a novel community program providing meals consistent with the planetary health diet to low-income families. This program attempts to overcome some of the limitations of other food assistance programs.

The largest program addressing food insecurity in the U.S. is SNAP, which cost US $\$ 60.3$ billion in 
Figure 1. Responses of 242 Participants in Food That Connects Us All to Four Questions in a Food Survey

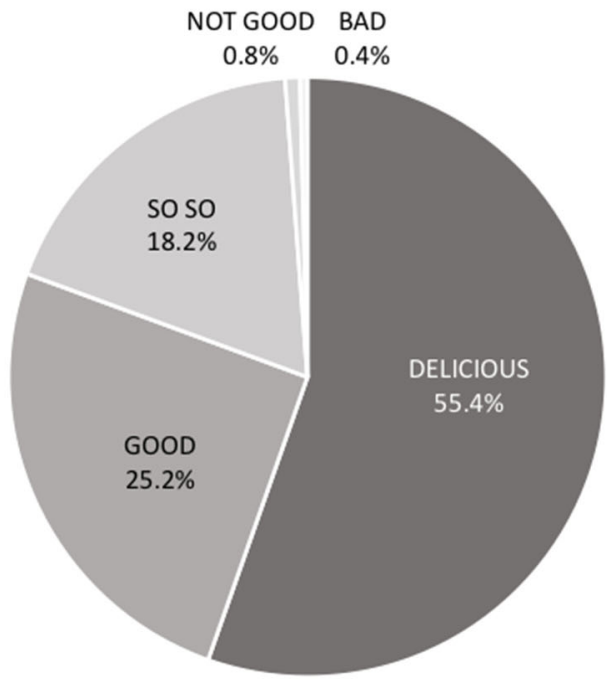

TASTE

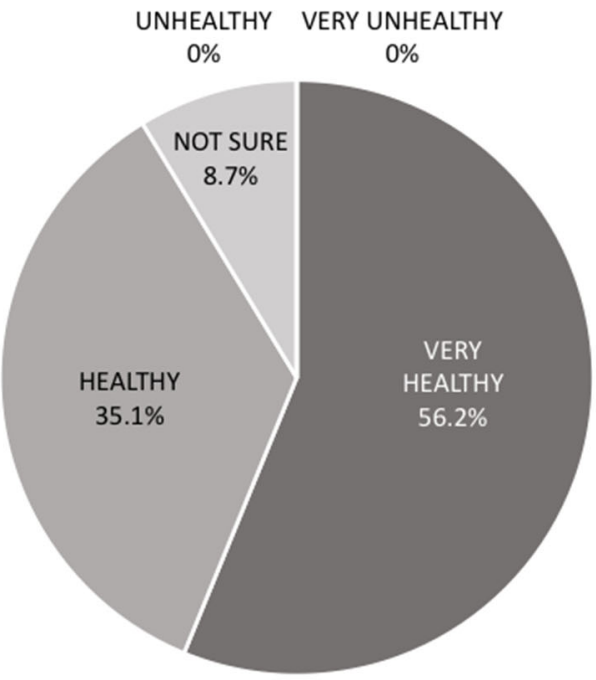

HEALTHY

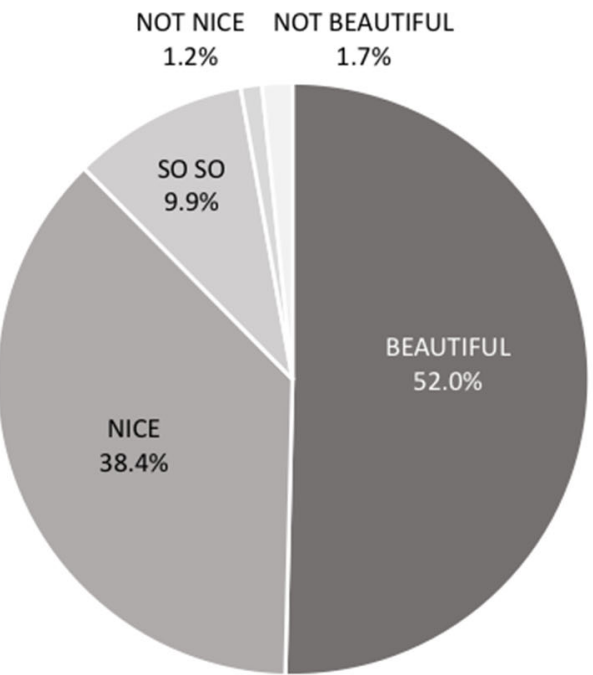

APPEARANCE

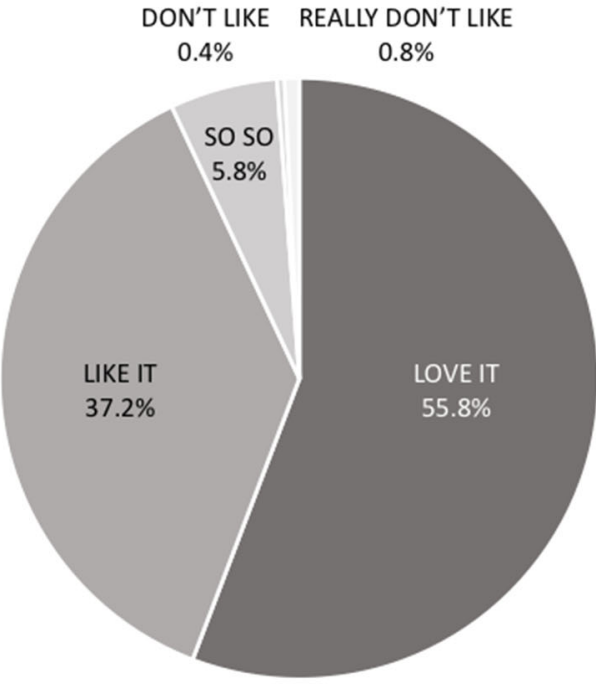

OVERALL SATISFACTION

2019 (Duffin, 2020). Retailers can accept SNAP funds for essentially any food product, including candy, chips, sodas, doughnuts, and other convenience foods; analyses from the National Health and Nutrition Examination Survey show that participants were likely to make food choices that have relatively poor dietary quality (Leung et al., 2012a). Among children 2 to 17 years old, SNAP recipients were more likely to consume sugar-sweetened beverages and to be overweight or obese compared to those who did not receive SNAP benefits (Twarog et al., 2020). SNAP participants have a higher consumption of sugarsweetened beverages compared to some SNAP-eligible nonparticipants (Nguyen \& Powell, 2015). SNAP 
has been implicated in increasing both diet and health disparities (Fang Zhang et al., 2018). SNAP participants are at higher risk of hypertension, cardiovascular disease, diabetes, and have higher risk of all cause, cardiovascular, and diabetes mortality compared with other American adults (Conrad, Rehm, Wilde, \& Mozaffarian, 2017; Leung, Willett, \& Ding, 2012b; Nguyen, Shuval, Bertmann, \& Yaroch, 2015). In order to increase access to staple foods in high-priority food areas, SNAP was updated with standards to increase the "depth of stock" of healthier foods. In Baltimore City, however, the barriers to providing better foods in food deserts have included low customer demand and the potential for food spoilage (Ross, Krishnan, Ruggiero, Kerrigan, \& Gittelsohn, 2018).

Food banks, which were traditionally established to alleviate hunger, are another source of food for low-income families. Many food banks have difficulties providing fresh fruit and vegetables, and not all leaders of food banks consider their organizations to be agents for change to promote health and reduce chronic disease (Wetherill, White, \& Seligman, 2019). Many food banks do not want to turn down food, even though it may not be considered healthy (Wetherill et al., 2019). Other challenges with food banks include limited hours and the availability of mostly poor-quality foods (Bryan et al., 2019; Ginsburg et al., 2019).

A strength of Food That Connects $U s$ All is an innovative application of the planetary health diet in a vulnerable population at high risk for obesity (Flórez et al., 2019), diabetes (Aguayo-Mazzucato et al., 2019), and cardiovascular disease (Graham, 2015). The planetary health diet was formulated-based upon the strongest scientific evidence - as the reference diet for promoting health and longevity and staying within planetary boundaries (EAT-Lancet, 2020; Willett et al., 2019). The program in Baltimore shows the feasibility of applying this healthy reference diet in an urban setting. The responses to the survey showed a high rate of satisfaction with the food by the participants. According to one of the program directors, initially the meals were somewhat of a shock to some of the participants, who were accustomed to eating beef, pork, and highly processed foods and snacks (Irena Stein, personal communication, August 21, 2020). However, the participants expressed overall satisfaction with the meals.

The program provides meals on a daily basis, which allows for inclusion of fresh vegetables and fruit that have a limited shelf life. The program offered a reasonable working wage to cooks and personnel and supports locally sourced foods. The planetary health diet is sustainable for the planet; if the diet were adopted worldwide, there would be an estimated $23 \%$ reduction in agricultural global greenhouse gas emissions (Semba et al., 2020).

As noted above, meals are provided daily by the program. A more convenient alternative may be to supply a week's worth of food in one pickup; however, prepared fresh salads, fruit, vegetables, and dairy products may lose quality and appeal after storage in a refrigerator beyond a day or two. Nuts are not included in the meals because of concerns about nut allergies among the participants. The meals are relatively expensive, as the total cost of one meal, including food costs, food preparation, transport, and delivery, is US $\$ 10.00 /$ meal, compared with US $\$ 1.40 /$ meal provided by support from SNAP (Center for Budget and Policy Priorities, 2019). The long-term impact of these healthy meals on recipients' health outcomes is not known because the program was just recently initiated. The formulation of the planetary health diet is based on what is considered to be an ideal healthy reference diet that reduces risk of heart disease, diabetes, obesity, cancer, and mortality (EAT-Lancet, 2020; Willett et al., 2019). There may be long-term benefits in providing healthy food to high-risk, low-income families, such as reducing chronic diseases and the related health care costs (Jardim et al., 2019). Food That Connects Us All demonstrates the feasibility of providing an ideal reference diet during the COVID-19 pandemic to vulnerable, lowincome families who have a high risk for poor health outcomes. 


\section{References}

Aguayo-Mazzucato, C., Diaque, P., Hernandez, S., Rosas, S., Kostic, A., \& Caballero, A. E. (2019). Understanding the growing epidemic of type 2 diabetes in the Hispanic population living in the United States. Diabetes/Metabolism Research and Reviews, 35(2), e3097. https://doi.org/10.1002/dmrr.3097

Alaimo, K., Olson, C. M., \& Frongillo, E. A., Jr (2001). Food insufficiency and American school-aged children's cognitive, academic, and psychosocial development. Pediatrics, 108(1), 44-53.

Brown, A., Esposito, L. E., Fisher, R. A., Nicastro, H. L., Tabor, D. C., \& Walker, J. R. (2019). Food insecurity and obesity: Research gaps, opportunities, and challenges. Translational Behavioral Medicine, 9(5), 980-987. https://doi.org/10.1093/tbm/ibz117

Bryan, A. D., Ginsburg, Z. A., Rubinstein, E. B., Frankel, H. J., Maroko, A. R., Schechter, C. B., . . Lucan, S. C. (2019). Foods and drinks available from urban food pantries: nutritional quality by item type, sourcing, and distribution method. Journal of Community Health, 44(2), 339-364. https:/ / doi.org/10.1007/s10900-018-0592-z

Center for Budget and Policy Priorities. (2019, November 7). Chart Book: SNAP Helps Struggling Families Put Food on the Table. Retrieved August 8, 2020, from https://www.cbpp.org/research/food-assistance/chart-book-snap-helps-struggling-families-put-food-on-the-table

Conrad, Z., Rehm, C. D., Wilde, P., \& Mozaffarian, D. (2017). Cardiometabolic mortality by Supplemental Nutrition Assistance Program participation and eligibility in the United States. American Journal of Public Health, 107(3), 466474. https://doi.org/10.2105/AJPH.2016.303608

Cook, J. T., Frank, D. A., Berkowitz, C., Black, M. M., Casey, P. H., Cutts, D. B., . . Nord, M. (2004). Food insecurity is associated with adverse health outcomes among human infants and toddlers. Journal of Nutrition, 134(6), $1432-1438$. https://doi.org/10.1093/jn/134.6.1432

Duffin, E. (2020). U.S. Supplemental Nutrition Assistance Program (SNAP): Total costs 1969-2019. Statista. Retrieved July 31, 2020, from https://www.statista.com/statistics/315032/us-supplemental-nutrition-assistance-program-total-costs/

Dunn, C. G., Kenney, E., Fleischhacker, S. E., \& Bleich, S. N. (2020). Feeding low-income children during the Covid-19 pandemic. New England Journal of Medicine, 382(18), e40. https://doi.org/10.1056/NEJMp2005638

EAT-Lancet. (2020). The planetary health diet. Retrieved July 31, 2020, from https://eatforum.org/learn-and-discover/the-planetary-health-diet/

Fang Zhang, F., Liu, J., Rehm, C. D., Wilde, P., Mande, J. R., \& Mozaffarian, D. (2018). Trends and disparities in diet quality among US adults by Supplemental Nutrition Assistance Program participation status. JAMA Network Open, 1(2), e180237. https://doi.org/10.1001/jamanetworkopen.2018.0237

Flórez, K. R., Katic, B. J., López-Cevallos, D. F., Murillo, R., Cancel-Tirado, D., Aponte-Soto, L., \& Echeverria, S. E. (2019). The double burden of food insecurity and obesity among Latino youth: Understanding the role of generational status. Pediatric Obesity, 14(9), e12525. https://doi.org/10.1111/ijpo.12525

Franco, M., Diez Roux, A. V., Glass, T. A., Caballero, B., \& Brancati, F. L. (2008). Neighborhood characteristics and availability of healthy foods in Baltimore. American Journal of Preventive Medicine, 35(6), 561-567. https://doi.org/10.1016/j.amepre.2008.07.003

Ginsburg, Z. A., Bryan, A. D., Rubinstein, E. B., Frankel, H. J., Maroko, A. R., Schechter, C. B., . . Lucan, S. C. (2019). Unreliable and difficult-to-access food for those in need: A qualitative and quantitative study of urban food pantries. Journal of Community Health, 44(1), 16-31. https://doi.org/10.1007/s10900-018-0549-2

Graham G. (2015). Disparities in cardiovascular disease risk in the United States. Current Cardiology Reviews, 11(3), 238245. https://doi.org/10.2174/1573403x11666141122220003

Hanson, K. L., \& Connor, L. M. (2014). Food insecurity and dietary quality in US adults and children: A systematic review. American Journal of Clinical Nutrition, 100(2), 684-692. https://doi.org/10.3945/ajcn.114.084525

Hernandez, D. C., Reesor, L. M., \& Murillo, R. (2017). Food insecurity and adult overweight/obesity: Gender and race/ethnic disparities. Appetite, 117, 373-378. https://doi.org/10.1016/j.appet.2017.07.010 
Holben, D. H., \& Marshall, M. B. (2017). Position of the Academy of Nutrition and Dietetics: Food insecurity in the United States. Journal of the Academy of Nutrition and Dietetics, 117(12), 1991-2002. https://doi.org/10.1016/j.jand.2017.09.027

Huang, J., Kim, Y., \& Birkenmaier, J. (2016). Unemployment and household food hardship in the economic recession. Public Health Nutrition, 19(3), 511-519. https://doi.org/10.1017/S1368980015001603

Jardim, T. V., Mozaffarian, D., Abrahams-Gessel, S., Sy, S., Lee, Y., Liu, J., . . . Gaziano, T. A. (2019). Cardiometabolic disease costs associated with suboptimal diet in the United States: A cost analysis based on a microsimulation model. PLoS Medicine, 16(12), e1002981. https://doi.org/10.1371/journal.pmed.1002981

Kinsey, E. W., Kinsey, D., \& Rundle, A. G. (2020). COVID-19 and food insecurity: An uneven patchwork of responses. Journal of Urban Health: Bulletin of the New York Academy of Medicine, 97(3), 332-335. https://doi.org/10.1007/s11524-020-00455-5

Leung, C. W., Ding, E. L., Catalano, P. J., Villamor, E., Rimm, E. B., \& Willett, W. C. (2012a). Dietary intake and dietary quality of low-income adults in the Supplemental Nutrition Assistance Program. American Journal of Clinical Nutrition, 96(5), 977-988. https://doi.org/10.3945/ajcn.112.040014

Leung, C. W., Willett, W. C., \& Ding, E. L. (2012b). Low-income Supplemental Nutrition Assistance Program participation is related to adiposity and metabolic risk factors. The American Journal of Clinical Nutrition, 95(1), 17-24. https://doi.org/10.3945/ajcn.111.012294

Loopstra R. (2018). Interventions to address household food insecurity in high-income countries. Proceedings of the Nutrition Society, 77(3), 270-281. https://doi.org/10.1017/S002966511800006X

Montenovo, L., Jiang, X., Rojas, F. L., Schmutte, I. M., Simon, K. I., Weinberg, B. A., \& Wing, C. (2020). Determinants of disparities in Covid-19 job losses (National Bureau of Economic Research Working Paper No. 27132). https://doi.org/10.3386/w27132

Nguyen, B. T., \& Powell, L. M. (2015). Supplemental nutrition assistance program participation and sugar-sweetened beverage consumption, overall and by source. Preventive Medicine, 81, 82-86. https://doi.org/10.1016/i.ypmed.2015.08.003

Nguyen, B. T., Shuval, K., Bertmann, F., \& Yaroch, A. L. (2015). The Supplemental Nutrition Assistance Program, food insecurity, dietary quality, and obesity among U.S. adults. American Journal of Public Health, 105(7), 1453-1459. https://doi.org/10.2105/AJPH.2015.302580

Niles, M. T., Bertmann, F., Belarmino, E. H., Wentworth, T., Biehl, E., \& Neff, R. (2020). The early food insecurity impacts of COVID-19. Nutrients, 12(7), E2096. https://doi.org/10.3390/nu12072096

Preamble to the Constitution of WHO as adopted by the International Health Conference, New York, 19 June - 22 July 1946; signed on 22 July 1946 by the representatives of 61 States (Official Records of WHO, no. 2, p. 100) and entered into force on 7 April 1948.

Ross, A., Krishnan, N., Ruggiero, C., Kerrigan, D., \& Gittelsohn, J. (2018). A mixed methods assessment of the barriers and readiness for meeting the SNAP depth of stock requirements in Baltimore's small food stores. Ecology of Food and Nutrition, 57(2), 94-108. https://doi.org/10.1080/03670244.2017.1416362

Ryu, J. H., \& Bartfeld, J. S. (2012). Household food insecurity during childhood and subsequent health status: The early childhood longitudinal study_kindergarten cohort. American Journal of Public Health, 102(11), e50-e55. https://doi.org/10.2105/AJPH.2012.300971

Seligman, H. K., Laraia, B. A., \& Kushel, M. B. (2010). Food insecurity is associated with chronic disease among lowincome NHANES participants. Journal of Nutrition, 140(2), 304-310. https://doi.org/10.3945/jn.109.112573

Semba, R. D., de Pee, S., Kim, B., McKenzie, S., Nachman, K., \& Bloem, M. W. (2020). Adoption of the 'planetary health diet' has different impacts on countries' GHG emissions. Nature Food, 1, 481-484. https://doi.org/10.1038/s43016-020-0128-4

Twarog, J. P., Peraj, E., Vaknin, O. S., Russo, A. T., Woo Baidal, J. A., \& Sonneville, K. R. (2020). Consumption of sugar-sweetened beverages and obesity in SNAP-eligible children and adolescents. Primary Care Diabetes, 14(2), 181185. https://doi.org/10.1016/i.pcd.2019.07.003 
U.S. Department of Agriculture, Economic Research Service [USDA ERS]. (n.d.). Child Nutrition Programs. Retrieved July 31, 2020, from https://www.ers.usda.gov/topics/food-nutrition-assistance/child-nutrition-programs/

USDA ERS. (2020). Food security in the U.S. Retrieved July 31, 2020, from https://www.ers.usda.gov/topics/food-nutrition-assistance/food-security-in-the-us

USDA Food and Nutrition Service [USDA FNS]. (2020a). Nutrition Assistance Programs Key Data Release. April Key Data Report (February 2020 Data). Retrieved from https://fns-prod.azureedge.net/sites/default/files/data-files/Keydata-February-2020.pdf

USDA FNS. (2020b). Documents and Resources. WIC Data Tables. Annual State-Level Data FY 2014 - 2019. Retrieved from https://fns-prod.azureedge.net/sites/default/files/resource-files/26wifypart-7.pdf

U.S. Department of Labor, Bureau of Labor Statistics. (2020). The employment situation - June 2020. Washington, D.C.: United States Department of Labor. Retrieved from https://www.bls.gov/news.release/pdf/empsit.pdf

Walker, R. J., Chawla, A., Garacci, E., Williams, J. S., Mendez, C., Ozieh, M. N., \& Egede, L. E. (2019). Assessing the relationship between food insecurity and mortality among U.S. adults. Annals of Epidemiology, 32, 43-48. https://doi.org/10.1016/j.annepidem.2019.01.014

Wetherill, M. S., White, K. C., \& Seligman, H. (2019). Charitable food as prevention: Food bank leadership perspectives on food banks as agents in population health. Community Development, 50(1), 92-107. https://doi.org/10.1080/15575330.2019.1570961

Whitaker, R. C., Phillips, S. M., \& Orzol, S. M. (2006). Food insecurity and the risks of depression and anxiety in mothers and behavior problems in their preschool-aged children. Pediatrics, 118(3), e859-e868. https://doi.org/10.1542/peds.2006-0239

Willett, W., Rockström, J., Loken, B., Springmann, M., Lang, T., Vermeulen, S., . . Murray, C. J. L. (2019). Food in the Anthropocene: The EAT-Lancet Commission on healthy diets from sustainable food systems. Lancet, 393(10170), 447-492. https://doi.org/10.1016/S0140-6736(18)31788-4 